\title{
CERTAIN ASPECTS OF THE SOCIAL PROTECTION SYSTEM IN THE CONTEXT OF MODERNIZATION OF SOCIETY
}

\author{
Markaev Zokir Eshkulovich \\ Candidate of philosophical sciences, \\ Associate Professor, \\ Head department of Humanities at TSAU
}

\author{
Kholikulov Eldor Bakhromovvich \\ Tashkent State Agrarian University Assistant \\ Teacher, \\ Department of Humanities, \\ Tashkent, Uzbekistan
}

\begin{abstract}
This article highlights the fact that social protection of the population in the context of modernization of public life is an urgent problem. Analyses based on the views of Western and Eastern scientists on social protection of the population are also presented. In particular, certain aspects related to social protection, poverty reduction, education reform, increased employment and real income of the population were scientifically studied. The article provides a comparative analysis of Uzbek and international experience in addressing these issues.
\end{abstract}

KEY WORDS: social modernization, social policy, stability, reform, social justice.

\section{I.INTRODUCTION}

At a time when global risks arise, the state takes responsibility for maintaining a stable socioeconomic position of its citizens in society. There is no doubt that the strategy chosen for a socially oriented state is the only real and correct way to develop Uzbekistan, which is striving to take its place among the developed countries of the world. After all, today the goal and content of social modernization is to prepare society for life in a new industrial and innovative economy, accelerate sustainable and economic development of the country, improve interethnic relations, and establish social relations based on the principles of law and justice.

A socially oriented state is a new type of social relations between people based on the principles of social justice, social partnership and consent of citizens.

Based on the action strategy for the five priority areas of development of the Republic of Uzbekistan in 2017-2021, as well as the meaning of a number of published state programs, the continuity and continuity of the social protection system is ensured. The fourth of these five priority areas provides for the development of the social sphere. It was stated as follows:"Consistent increase in employment and real incomes of the population aimed at the development of the social sphere, implementation of targeted programs to improve the system of social protection and health protection, increase the socio-political activity of women, construction of affordable housing, development and modernization of road transport, engineering, communication and social infrastructure, development of education, culture, science, literature, art and sports, improvement of state youth policy" [1.92].

The tasks set in this direction are primarily considered as a consistent continuation of the great work done in these areas during the years of independence.

\section{METHOD}

The article uses chronological and systematic periodic data, comparative and quantitative methods. More than ten scientific papers on the topic are used to explainin"Certain aspects of the social protection system in the context of modernization of society". In addition, the researcher used different materials to collect data related to the study.

\section{DISCUSSION}

The fourth of the five principles developed by the First President of the Republic of Uzbekistan, Islam Karimov, during the transition period, which was called the "Uzbek model" in the world, was to conduct a strong social policy taking into account the complex demographic composition of the population. Even the essence of the reforms carried out in our country by international experts was called "Transition to a socially oriented market economy". This was no accident. 
Because the transition from one socio-political system to another, especially to a socio-political one that completely contradicts its essence, will always be difficult. This dramatically affects the lives of a certain part of the population. In the transition from one structure to another, in particular, the old production system and the existing economic integration will naturally fail, and the bar will have to be re-formed. The form of ownership is also changing, state-owned enterprises are changing, even the owners of cultivated land are changing, and the labor force is being redistributed directly according to the laws of the market economy. This means that the ranks of people in need of social protection are changing, that is, they are shrinking and increasing. "According to humanist scientists, $95-98 \%$ of the knowledge about existence accumulated so far is devoted to the problems of society, while data representing human nature make up less than one percent of knowledge"[2.-33].

This means that today we will not do such things, problems and tasks, one question in its essence "There is a common criterion that unites all of this. If this is so, then the person, their life dreams and concerns are clearly shown by the example of our aspirations to make people light' Ensuring the interests of the person, improving the social protection system is our priority [3.].Strong social policy to date defined by the President of our Republic, is a principle aimed at a strong social policy, which is an important aspect of the five principles of transition to a market economy, that is targeted, comprehensive support of the poor, poor families, disabled children and orphans, and lonely elderly people. Scientists note that the roots of our experience in this direction go to the religious, philosophical, historical basis and practical expression of our rich spiritual heritage. Given the history of our national state, the role of the state in the sphere of social policy was exceptional, and there was also a strong spiritual and ideological system designed to help the poor who needed the support of others. In this regard, Amir Temur, as an example, we can cite the good deeds, life and activities of our ancestors, such asA.Navoi, KhojaAhrorValiy.

The main issue in the history of the state and society, as well as in the process of its democratic development, is the peace of citizens, their comprehensive care, material and spiritual protection. In the history of reasoning, many valuable thoughts have been expressed about caring for people. According to Abu Nasr Farabiy, the people of a virtuous can help each other achieve happiness, support each other, ease pain, unite on the path to a single goal and thus achieve a virtuous: "The people of an ignorant city do not seek happiness, they do not even know what happiness is, because the people of ignorance have never found happiness and do not believe in happiness. As for welfare, people of ignorance (not knowing the true good, some see it as the past, superficial things, the world of goods, physical tastes, charm, practice, fame as true happiness, fairway) that seem happy in the eyes of some. Each of these blessings seems to be a goal, happiness in the eyes of ignorant people" [443.].AlisherNavoi says that people's attitude to the welfare of people in society is the most important work in the ruling activity. He stops at the fact that in 20 chapters of the poem "Khairat-ulAbror"generous (hotamtoy) is divided into three types, tells that a real generous found his vocation and gives the orphans what he grew up, and that people remember his noble deeds for life. MirzoHaidar Douglass's work "TarikhiRashidi" consists of two volumes, mostly written between 1541 and 1545. In the work, we can say that GreatNavoi was friendly with Sultan Hussein from childhood, later served his Palace, patronized the craftsmen of goodness, built many minarets, buildings, mosques, thoughts about the subtleties of knowledge, according to other historical sources, the poet's father was a Uyghur bakhshi(Singer), and opinions that he was a simple man do not have a historical basis[5-123].

Therefore, if the process of transition to a market economy does not create a guaranteed system of social support for the vulnerable part of the population in need of protection, this can lead to severe social shocks. In independent Uzbekistan, from the very beginning, this direction was reasonable.

This model of development, which embodies the characteristics of the people of Uzbekistan and best international practices, is also based on the goal of a strong social policy.Social protection of the population is one of the most important tasks in a market economy. The social protection system acts as a category that includes social problems that need to be addressed by society during the current economic reforms.

At the end of the XIX and beginning of the XX century, the first stage of the formation of the social protection system was implemented. At this stage, a number of laws on social protection were developed in European countries. In order to improve the social protection of the population, social insurance issues were developed. [6.] In the 30 s of the XX century, an economic crisis occurred in European countries. As a result, unemployment among the population has increased, incomes have decreased, and living conditions have deteriorated. In order to solve such problems, European countries and the United States have created schools that study the living conditions of the population. In the $30-40$ s of the XX century, representatives of the "school of population scientists"appeared in the United States"such as F. Roethlisberg, M. Follet and others conducted research among the population on social protection of the population. According to them, technology in the industry is managed by people, so the introduction of new technologies in the industry makes it easier for workers to work. After the Second world war, a number of countries formed a unified social security system[7].

Now we have created conditions for caring not only for the active part of the population, but also 
for all segments of the population, their social security, as well as providing medical care to patients. In developed countries, the role of the state in the social protection system has increased. The state implemented a strong social policy in the field of managing and controlling the relationship between producers and employees, improving the social protection system of the population. The study showed that the social protection system of the population in different countries is related to the level of socio-economic development of the country. It should also be noted that in the trends related to the modernization of the social system in the world community itself, one of the important criteria is that the population of each country actively participates in the ongoing reforms[8].

Itcannot be said that an effective system of social protection of the population in the country is a sign of socio-economic development of modern societies. In a country where the economy is thriving, you can see a rapid increase in the standard of living of the population. In this country, every person, regardless of social origin, finds his place in society, fully uses his working capacity, and his rights are guaranteed by the state. The concept of social protection of the population is presented in many literatures, which mainly understand the social policy of the state.

According to professor K. Kh. Abdurakhmanov, social protection of the population is a system of direct targeted guarantees that ensure the conditions that the state provides to the population for normal life. In other words, the social protection system should be organized in accordance with a narrow view of the effectiveness of the market system, and not to address issues of ensuring real socio-economic efficiency[9.-9]. At the same time, it is necessary that social protection, each time acting on its own system of industrial relations, make extensive use of the opportunities of the current state of the world economy and develop on the basis of modern requirements.

It is known that the law, the development of society or nature express internal connections and begin to find their concrete expression in social development. First of all, everyone should understand the law correctly and turn it into a public domain. "The law is supposed to be the walls of our house," said the ancient Chinese scholar Confucius. Serves to improve the laws of philosophical Outlook, thinking, increase spirituality, material well-being of people.The harmonization of social protection with democratic processes and the real life of people consist in a person's awareness of their dignity in social space and time, without deviating from ethical norms, as well as in spiritual and educational formation. The state is constantly paying attention to the issue of ensuring the conditions associated with human life in social protection, old age extinguishment, responsibility, as in the brochure. Like saying:"A house that has a mermaid in it, a house that has a magic angel growing old, a state that pays attention to the elderly, is rich and serf-like. It should be noted that in the successful implementation of social protection, socio-political democratization and modernization are important. The word "Democracy" as a political and philosophical concept expresses such multi-colored phenomena as the power of the people, the electoral system, human rights, freedom of thought, conscience, parliamentary, political consciousness and political culture, participation in the management of the Affairs of society and the state, a free way of life [10-413].].

It is obvious that democracy is a sociopolitical activity, behavior related to governance. National (spiritual) self-consciousness is a form of thinking of social consciousness. The goal of national development is to harmonize this process, i.e. the form of social consciousness (subjective factor) and the democratic process (objective factor).

The conscious thinker can fully realize his reputation, his dignity. Any negative manifestations that are not susceptible to information attacks. When performing each work, measure it on the scale of intelligence, make the right conclusions and on this basis do the work. The new form of thinking dictates a real approach to the problems of life from the point of view of nationalism and humanity. Every person involved in the process of social protection that takes place in society will have to feel like an active participant in this process and, as a result, offend it. The famous Russian philosopher I. N.Bulgakov noted that for social protection, first of all, it is necessary to awaken people's passionate interest in life and ensure that their psyche is healthy[11-].Some scientists have tried to explain social protection of the population by the following systems: first, the social security system; second, the employment system; third, the system of social benefits for certain citizens, and so on. This approach reflects the role of the state in solving existing problems. The state regulates the level of social protection of the population by legislative and legislative acts, sets the minimum level necessary for survival, and, having provided for it, sets the minimum wage, social payments, insurance premiums and social assistance, types of benefits, coordinates the activities of services in the field of social protection. However, the most influential role of the state in managing the level of social protection of the population is to create additional jobs, including for people with disabilities, to help the population in vocational training, retraining and advanced training. Also, in turn, social protection includes:

Social assistance-free transfer of money to those in need or to households (White, 2016: 1) in cash, voucher, or in kind (including school meals); community service programs; payment waivers (for basic medical and educational services); and subsidies (such as food, fuel).

Social insurance is"Payment programs that include compensatory assistance in the event of illness, injury, disability, death of a spouse or parent, maternity/paternity, unemployment, old age, and unforeseen circumstances related to Pets/crops." Social 
assistance services are designed for those who face social risks such as violence, exploitation, discrimination and social loneliness."

Labor market programs- "active (promoting participation in the labor market) or passive (ensuring minimum employment standards)".

Social assistance and social insurance together constitute "social security, which is often replaced by the ILO and other UN bodies with social protection [11-20-21.].

\section{RESULTS}

In the context of the renewal of society, the leadership of our country has been implementing a powerful social policy strategy based on a "socially oriented market economy"since the first days of independence."Many people in Uzbekistan know the principles of transition to market relations. They don't need to sit back. But it is worth emphasizing the principle of strong social protection, because the implementation of other principles depends on it. In the conditions of transition to market relations, the priority of the economy in relation to ideology, the state's implementation of reforms and the rule of law serve the social protection of the population of our country. This is of particular importance for the Republic, where almost half of the working-age population is engaged in agriculture, up to 80 percent even in some places, 50 percent are children less than 18 years of age," said I. A. Karimov. 12-256.]. Was developed and adopted a series of laws concerning social protection of the disabled, youth policy and increase the role of women in society and the state, as well as on other issues a number of decrees and regulations in support of needy layers of the population, workers of budgetary organizations (soldiers, workers in education, health, sports, culture, etc.). These reforms allowed, on the one hand, preserving and enriching the spiritual and educational potential that has come down to us, and, on the other, to strengthen state support for market reforms.

Life is always in motion. In no case should you stop it for a moment or turn the wheel of history back. As society constantly moves forward, so does consciousness.

The essence of the changes is directly related to the individual, its interests, and the responsibility for the reforms is also directly borne by the citizen. As you can see, strong social protection has always been one of the priorities of the state policy of independent Uzbekistan. In our country, the main part of the state budget is directed to the social sphere, and this is strictly observed.

In Islam Karimov's book "Uzbekistan-a special way of transition to market relations", published in 1993, the seventh chapter entitled "Strong social policy - a reliable guarantee of economic transformation" comprehensively and in detail analyzes the principle of conducting a strong social policy.
This means that the main goal of the reforms is to improve the life of the people, ensure free living, develop citizens, actively work creatively, lead a productive life, and improve well-being. The fourth priority area of the Strategy, action which is dedicated to the development of the social sphere, attracts even more people's attention by the relevance and relevance of the issue we have raised. The main goal of the reform is to improve the quality of social protection of needy families and vulnerable segments of the population, the extensive reforms in health care, increasing the role and participation of women in public and political life, protection of motherhood and childhood, emergency assistance, and other necessary measures.

Therefore, in the Message of President Sh. Mirziyoyev to the country's Parliament dated January 24,2020 , it is no secret that most of the population in the regions, especially in villages, does not have a sufficient source of income. As in any country, we have low-income segments of the population. According to various estimates, they are about $12-15$ percent. We are not talking about small numbers, but about 4-5 million representatives of our population" [13.256], - he noted, - this is also a reflection at the state level of the problems inherent in the practical process.

Reducing poverty is the implementation of a comprehensive economic and social policy to stimulate the entrepreneurial spirit of the population, the full realization of the inner strength and potential of a person, and the creation of new jobs stressed, President Sh.Mirziyoyev[14.-592].

At the same time, in the context of the current pandemic, as well as various natural and man-made disasters, the work carried out in our country in the field of social support and comprehensive protection of the population demonstrates a high level of humanity. In particular, the 2030 agenda and sustainable development goals (BRM) will provide a framework for fighting poverty in all countries. In such circumstances, social protection systems play an important role, since they are aimed at protecting the population from social, economic and natural risks. In addition, effective social protection systems promote the active participation of all population groups in economic growth processes, reduce inequality, and thus contribute to sustainable and inclusive social development. For this reason, many countries include in their national development strategies and plan the creation and expansion of comprehensive social protection systems that ultimately provide income security and support for all people in the life cycle.

Despite this progress, $73 \%$ of the world's population has only partial or no access to complex social protection systems. Many developed and developing countries seek to link their efforts to the principles of the 2030 agenda, and its main goal is to ensure well-being for all based on a common partnership based on human dignity. 


\section{V.CONCLUSIONS}

First, the social policy of the state is characterized by the preliminary result of the state's reforms aimed at maintaining social stability and improving the standard of living of the population.

Secondly, ensuring the continuity and continuity of the social protection system in today's global crises (social crises, pandemics, etc.) is important in the context of.

Third, the study shows that the system of social protection of the population in different States is related to the level of socio-economic development of the country.

Based on a comprehensive in-depth study of world experience, taking into account the mentality of our people, the market economy should be socially oriented and, above all, oriented to the interests of society. Based on this, it is necessary to increase the social effectiveness of economic reforms by implementing policies aimed at the activities of civil society institutions, including political parties, in the interests of segments of the population in need of state and public support.

Fourth, based on the needs of enterprises and organizations in the system of secondary special education, the development of training practices is crucial both in terms of employment of graduates, and in terms of the development of industries, production, service and service. At the same time, ensuring selfemployment of graduates of professional colleges, further improving the provision of preferential microcredits for them to start self-employment and business activities,

Fifthly, it should be remembered that ensuring social stability is important for the multi ethnic population of Uzbekistan, the main goal of the reforms is to improve the life of the people, active participation of citizens in free living, development, creative work, fruitful conduct of life, and improving welfare.

\section{LIST OF USED LITERATURE}

1. On the Strategy for further development of the Republic of Uzbekistan:Decree of the President Of The Republic Of Uzbekistan. - Tashkent: publishing and printing creative house named after GafurGulyam, 2017. - 92 b.

2. Science and life. 1997. 3rd ed. - 33 P.

3. Karimov I. A. Uzbekistan is a special way of transition to market relations.

4. Abu Nasr Farabi. "City of suffering people". // - T. "Chulpan" 2004. - 43B.

5. G. Sirozhiddinov "AlisherNavoi: comparative typological, textual analysis of sources", Vol.: Akad. 2011. 123-bet.

6. Lepekhov M. I. Legal and social cohesion of the population in Russia. - Moscow, Moscow, 2000.

7. Khashimov P. Z. Social sphere of economy T.: "University" 2002
8. Inglehart $V ., \quad K . \quad$ Velzel. Development and democracy: we know about modernization. // Sociology. 1/2011.

9. Abdurakhmanov K. X, TohirovaKh. T., Sharipov B. M. "Social protection of the population"- (texts of may decrees) - T.: TSU, 2005. - B. 9.

10. Gadzhiev K. S. Epoha in democracy. //// Question of philosophy. 1996. no. 3. - P. 4-13; M. V., Melville A. Yu., Fedorov Yu. E. Democracy I democratization // police. 1996. No. 4. - P. 142164 ;

11. Nudenko L. A. Theory of democracy, Moscow: Yurist, 2001, Pp. 41-62.

12. Sepulveda \&Nyst, 2012: 20-21; ILO, 2017

13. Karimov I. A. Uzbekistan: national independence, economy, politics, ideology. Vol. 1.: Uzbekistan, 1996. 256-page.

14. MirziyoyevSh.M. We firmly continue our path of national development and will rise to a new level. Vol. 1.: - Tashkent: NMI of Uzbekistan, 2017. 592 $b$. 